\title{
A STUDY OF SONOGRAPHIC EVALUATION OF FETAL FEMUR LENGTH FOR ESTIMATION OF GESTATIONAL AGE
}

\section{Monika Adhvaryu ${ }^{1}$, Ankit Adhvaryu *2, Suresh P. Rathod ${ }^{3}$, Pradip R. Chauhan ${ }^{4}$.}

${ }^{1}$ Tutor in Anatomy, M. P. Shah Government Medical College, Jamnagar, Gujarat, India.

${ }^{* 2}$ Assistant professor in Anatomy, M. P. Shah Government Medical College, Jamnagar, Gujarat, India.

${ }^{3}$ Dean, GMERS medical College, Junagadh, Gujarat, India.

${ }^{4}$ Tutor in Anatomy, P. D. U. Government Medical college, Rajkot, Gujarat, India.

\section{ABSTRACT}

Introduction: Accurate estimation of Gestational age is of great value in proper obstetric care and intervention during pregnancy. Ultrasound has evolved as a reliable method for accurate measurement of gestational age by measuring various fetal biometric features like Crown Rump Length (CRL), Biparietal Diameter (BPD), Femur length (FL), Abdominal Circumference (AC), Head Circumference (HC), Trans Cerebellar Diameter (TCD) etc. Femur being the longest bone in fetus, least movable and easily imagable from second trimester to delivery, can be measured for estimation of gestational age. The present study was performed to evaluate femur length in second and third trimester by ultrasonography, assess gestational age from measurement of Femur Length (FL) and determine the accuracy of gestational age assessed by ultrasonography with gestational age assessed by LMP method in local population of Gujarat.

Materials and Methods: Cross sectional study of total of 200 pregnant women, 100 second trimester and 100 third trimester, between 13 and 40 weeks of gestational age attending the department of radiology at P.D.U. Medical college, Rajkot for a fetal ultrasound scan was done. Femur length (FL) was measured; Gestational age was measured by Hadlock's method and Loughna P et al's method; also gestational age was assessed from LMP of the women. The mean values of femur length and predictive accuracy of fetal femur length was analyzed and compared with other studies.

Results: Mean of FL increased progressively from 13-40 weeks of gestation. During both second and third trimesters, Hadlock's formula and Loughna P's method were equally accurate to assess the gestational age. But femur length was more accurate in second trimester than in third trimester. There was discrepancy in values of femur length as compared to other studies.

Conclusion: Like other studies the present study also found the need of fetal charts that were specific for individual population and ethnic group to determine gestational age and EDD to enable the development of better clinical guidelines for the present population.

KEY WORDS: Fetal Femur Length, Gestational Age.

Address for Correspondence: Dr. Ankit Adhvaryu, Assistant professor in Anatomy, M. P. Shah Government Medical College, Jamnagar, Gujarat, India. E-Mail: ankit_adhvaryu@yahoo.co.in

Access this Article online

Quick Response code

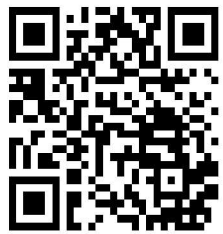

DOI: $10.16965 /$ ijar.2019.189
Journal Information

International Journal of Anatomy and Research

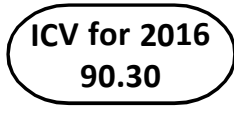

ISSN (E) 2321-4287 | ISSN (P) 2321-8967

https://www.ijmhr.org/ijar.htm

DOI-Prefix: https://dx.doi.org/10.16965/ijar

\section{Article Information}

Received: 29 Mar 2019

Peer Review: 29 Mar 2019

Revised: None
Accepted: 06 May 2019

Published (O): 05 Jun 2019

Published (P): 05 Jun 2019

\section{INTRODUCTION}

Gestational age, synonymous with menstrual age, is defined in weeks beginning from the first day of the last menstrual period (LMP) prior to 
conception [1]. The accurate knowledge of gestational age is the key for successful antepartum care and critical interpretation of antenatal tests and successful planning of appropriate intervention or treatment [2].

Ultrasound examination and measurement of fetal biometry has become an integral part of fetal evaluation during pregnancy [3]. Ultrasound is a reliable method for establishing the length of pregnancy and in this way can improve obstetric care [1]. The most commonly used fetal biometric parameters are crown rump length (CRL), Biparietal diameter (BPD), head circumference $(\mathrm{HC})$, abdominal circumference $(\mathrm{AC})$, femur length $(\mathrm{FL})$ to determine gestational age and growth in different trimesters [2].

Measurement of fetal limbs can be used to date pregnancies as well as forming an important part of the assessment of fetal anatomy [4]. All fetal long bones can be adequately examined and measured by ultrasound; however, femur is the largest of the long bones, least moveable, easiest to image and can be adequately visualized from early second trimester of gestation until delivery [1]. Femur length measurements may be used to accurately predict gestational age between 14 weeks gestation and term [1].

The present study was performed to evaluate femur length in second and third trimester by ultrasonography, assess gestational age from measurement of Femur Length (FL) and determine the accuracy of gestational age assessed by ultrasonography with gestational age assessed by LMP method in local population of Gujarat.

\section{MATERIALS AND METHODS}

The present study was a cross-sectional study conducted in the Department of Anatomy and Department of Radiology, at P.D.U. Medical College, Rajkot, Gujarat. The study involved a total of 200 pregnant women (no repetition), 100 second trimester and 100 third trimester, between 13 and 40 weeks of gestational age attending the department of radiology for a fetal ultrasound scan. The fetuses were measured using Philips Sonodiagnost 360 (NS981480701009) by trained operators, all of whom were performing more than 2000 ultrasound examinations per year at the time.
Radiology department had a certificate of registration for performing Ultrasonography under Pre-natal Diagnostic Technique (PNDT) Act 1994

The inclusion criteria for the study were:[4-7]

\section{Singleton pregnancy.}

2. Known date of beginning of the Last Menstrual Period (LMP)

3. Regular menstrual cycle close to 28 days.

4. Absence of fetal anomalies or intrauterine growth retardation (IUGR) detected at the time of ultrasound examination.

5. No history of maternal chronic diseases known to affect fetal size like diabetes, hypertension, renal disease etc.

6. No history of abnormal babies, still births or abortions.

7. No history of consumption of oral contraception pill (OCP)

No exclusions were made on the grounds of small-for-date birth weight [8]. Prior Permission was taken from the institutional ethical committee. During the study, first an informed consent was taken from the pregnant women who satisfied all the above criteria, by taking her signature in a completely filled Form - F (in compliance to PCPNDT Act) which was then signed by the radiologist conducting the sonography.

Fetal femur length (FL)[2,6,9]: The measurement was observed with a linear array transducer. It was measured in a plane where the full femoral diaphysis was seen almost parallel to the transducer. Disregarding any curvature, a straight measurement was made along the long axis of diaphysis from centre of one end of diaphysis, i.e. tip of greater trochanter to the other end, i.e. lateral epicondyle. In the third trimester, particular care was taken not to include the distal femoral epiphysis in the measurement.

Gestational age was calculated from the date of LMP.

Predictive gestational age from Femur length was assessed by two different formulas. 1) Hadlock's formula - gestational age was assessed from the USG machine, the software of which used Hadlock's formula to calculate 
gestational age. 2) As per formula given in Loughna $P$ et al. [10].

Gestational age (GA) was calculated in completed weeks.

Mean value and Standard deviation (SD) of each week of gestational age was calculated; the predictive accuracy of fetal femur length was analyzed.The data was statistically analysed for the significance and accuracy. All the calculations and analysis were done by using Microsoft Excel 2007 and Epi Info 7 software.
Fig. 1: Showing Femur Length in Ultra sonography.

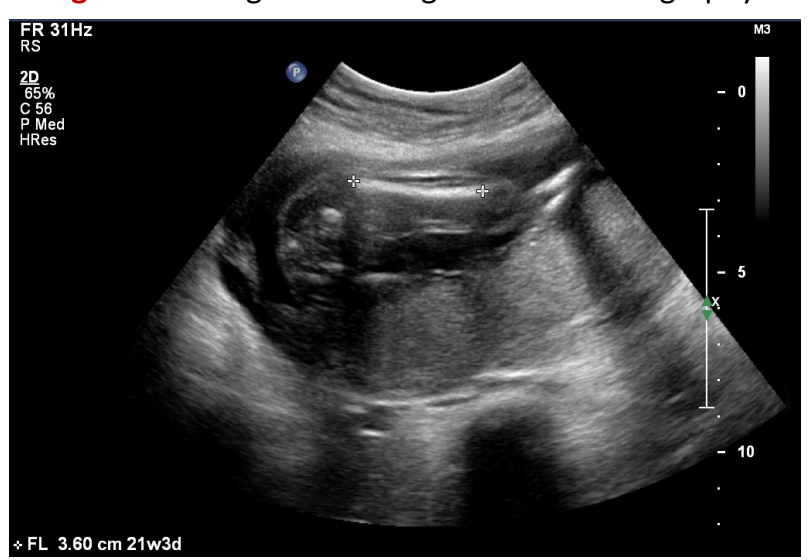

Table 1: Mean Femur Length (In $\mathrm{mm}$ ) Of Different Studies.

\begin{tabular}{|c|c|c|c|c|c|c|c|c|c|c|}
\hline \multirow{2}{*}{ GA (wks) } & \multicolumn{3}{|c|}{ Present Study } & \multirow{2}{*}{$\begin{array}{c}\text { Hadlock's Study } \\
1982[11]\end{array}$} & \multirow{2}{*}{$\begin{array}{c}\text { Hadlock's Study } \\
1983 \text { [15] }\end{array}$} & \multirow{2}{*}{$\begin{array}{c}\text { Seeds's } \\
\text { Study [19] }\end{array}$} & \multirow{2}{*}{$\begin{array}{l}\text { Lai FM's } \\
\text { Study [9] }\end{array}$} & \multirow{2}{*}{\begin{tabular}{|c|} 
Iranian \\
Population [20]
\end{tabular}} & \multirow{2}{*}{\begin{tabular}{|c|} 
Australian \\
Population [21]
\end{tabular}} & \multirow{2}{*}{$\begin{array}{c}\text { Babuta et al } \\
{[2]}\end{array}$} \\
\hline & $\mathrm{FL}$ & No. & SD & & & & & & & \\
\hline 13 & 12.33 & 3 & 2.08 & 11 & 11 & --- & --- & 10 & & 9.5 \\
\hline 14 & 12 & 1 & 0 & 14 & 15 & 15 & 17.67 & 12 & 15 & 12.38 \\
\hline 15 & 16 & 4 & 2.71 & 17 & 18 & 18 & 17.6 & 14 & 17 & 15.18 \\
\hline 16 & 18.33 & 3 & 3.51 & 20 & 21 & 20 & 19.5 & 17 & 22 & 18.73 \\
\hline 17 & 25.25 & 4 & 4.65 & 24 & 24 & 23 & 21.24 & 20 & 25 & 21.9 \\
\hline 18 & 28.14 & 7 & 3.39 & 27 & 27 & 26 & 26.06 & 23 & 28 & 24.8 \\
\hline 19 & 29 & 5 & 1.58 & 30 & 30 & 29 & 28.17 & 26 & 30 & 27.55 \\
\hline 20 & 34.2 & 5 & 4.15 & 33 & 33 & 32 & 30.66 & 29 & 32 & 30.2 \\
\hline 21 & 36.75 & 4 & 1.26 & 35 & 36 & 35 & 32.74 & 32 & 34 & 33.1 \\
\hline 22 & 38.58 & 11 & 5.3 & 38 & 39 & 37 & 35.26 & 35 & 37 & 35.13 \\
\hline 23 & 41 & 9 & 3.81 & 41 & 42 & 40 & 37.76 & 38 & 43 & 38.31 \\
\hline 24 & 43.2 & 5 & 1.1 & 44 & 44 & 42 & 40.65 & 40 & 45 & 41.5 \\
\hline 25 & 46.33 & 12 & 3.31 & 46 & 47 & 45 & 43.48 & 43 & 48 & 43.63 \\
\hline 26 & 49.8 & 5 & 4.55 & 49 & 49 & 48 & 45.49 & 45 & 49 & 45.42 \\
\hline 27 & 50.82 & 11 & 4.69 & 51 & 52 & 50 & 48.28 & 48 & 50 & 47.7 \\
\hline 28 & 54.64 & 11 & 3.38 & 54 & 54 & 53 & 50.54 & 50 & 54 & 49.86 \\
\hline 29 & 55.33 & 3 & 1.53 & 56 & 56 & 55 & 52.93 & 53 & 55 & 52.4 \\
\hline 30 & 56.1 & 10 & 2.92 & 58 & 58 & 57 & 54.98 & 55 & 58 & 54.79 \\
\hline 31 & 59.57 & 7 & 3.05 & 60 & 61 & 60 & 57.38 & 57 & 59 & 57.5 \\
\hline 32 & 61.2 & 10 & 2.2 & 62 & 63 & 62 & 59.03 & 60 & 62 & 60.4 \\
\hline 33 & 63.2 & 5 & 2.86 & 64 & 65 & 64 & 60.98 & 62 & 65 & 62.14 \\
\hline 34 & 64.55 & 11 & 3.53 & 66 & 66 & 67 & 62.8 & 63 & 66 & 63.08 \\
\hline 35 & 66.14 & 14 & 2.66 & 68 & 68 & 69 & 64.59 & 65 & 67 & 65.85 \\
\hline 36 & 67.22 & 9 & 3.15 & 70 & 70 & 71 & 65.53 & 67 & 69 & 66.59 \\
\hline 37 & 69.6 & 5 & 0.55 & 72 & 72 & 73 & 67.57 & 69 & 72 & 68.14 \\
\hline 38 & 71.89 & 9 & 3.79 & 74 & 73 & 76 & 68.63 & 71 & 73 & 69.14 \\
\hline 39 & 73.3 & 10 & 3.5 & 75 & 75 & 78 & 69.57 & 73 & 75 & 71.78 \\
\hline
\end{tabular}

Table 2: Difference in Estimation of Gestational age.

\begin{tabular}{|c|c|c|c|c|}
\hline \multirow{2}{*}{$\begin{array}{l}\text { Difference in GA } \\
\quad \text { (in weeks) }\end{array}$} & \multicolumn{2}{|c|}{ Second trimester } & \multicolumn{2}{|c|}{ Third trimester } \\
\hline & $\begin{array}{l}\text { Hadlock's } \\
\text { (N) }\end{array}$ & \begin{tabular}{|c|} 
Loughna P et al \\
(N)
\end{tabular} & $\begin{array}{l}\text { Hadlock's } \\
\text { (N) }\end{array}$ & $\begin{array}{c}\text { Loughna P et al } \\
\text { (N) }\end{array}$ \\
\hline$>3$ & 0 & 3 & 0 & $\begin{array}{c}0 \\
\end{array}$ \\
\hline 3 & 4 & 5 & 0 & 1 \\
\hline 2 & 4 & 5 & 1 & 7 \\
\hline 1 & 28 & 16 & 9 & 17 \\
\hline 0 & 36 & 34 & 21 & 24 \\
\hline-1 & 14 & 25 & 25 & 20 \\
\hline-2 & 7 & 8 & 24 & 18 \\
\hline-3 & 4 & 4 & 13 & 10 \\
\hline$<-3$ & 3 & 0 & 7 & 3 \\
\hline TOTAL & 100 & 100 & 100 & 100 \\
\hline
\end{tabular}


Table 3: Comparative study of difference in Estimation of Gestational age.

\begin{tabular}{|c|c|c|c|c|}
\hline Trimester & $\begin{array}{c}\text { Difference in GA } \\
\text { (Weeks) }\end{array}$ & $\begin{array}{c}\text { Present Study } \\
\text { (\% of cases) }\end{array}$ & $\begin{array}{c}\text { Babuta S. et al [2] } \\
\text { (\% of cases) }\end{array}$ & P value \\
\hline \multirow{4}{*}{ Second } & 0 & 36 & 40 & $>0.05$ \\
\cline { 2 - 5 } & \pm 1 & 42 & 54.55 & $>0.05$ \\
\cline { 2 - 5 } & $\geq-2$ & 14 & 3.02 & $<0.05$ \\
\hline \multicolumn{5}{|c|}{} \\
\hline \multirow{4}{*}{ Third } & 0 & 21 & 30.91 & $>0.05$ \\
\cline { 2 - 6 } & \pm 1 & 34 & 9.7 & $<0.001$ \\
\cline { 2 - 6 } & $\geq-2$ & 41 & 58.79 & $>0.05$ \\
\hline
\end{tabular}

\section{DISCUSSION}

Sonographic biometric measurements are the most extensively used method for estimation of fetal size and gestational age. Morsy et al [6] have quoted from Hadlock et al and Neufeld et al that biparietal diameter and femur length are routinely measured during every second and third trimester prenatal sonogram.

The present study was a cross-sectional study, in agreement with Hadlock et al[11], Browne et al[12], Snijders RJ et al[13] and Figueras et al[14]. They mentioned that, each fetus was measured once in contrast to longitudinal studies in which measurements of each fetus were made at different gestational ages [6].

In the present work, there was no pre selection for maternal age, parity or fetal sex. This was in agreement with the criteria of Mory M et al[6]. The sample size of the present study was 200 fetuses. This was smaller compared to that recorded by Hadlock et al $[11,15]$, Chitty et al[16], Snijders RJ et al[13] and Figueras et al[14].

As seen in Table 1, Overall, the mean Femur length (FL) increased from $12.33 \pm 2.08 \mathrm{~mm}$ at 13 weeks gestation to $74.29 \pm 2.36 \mathrm{~mm}$ at 40 weeks of gestation. As shown in table 1 in the present study, it was found that, the mean $\mathrm{FL}$ increased progressively from 13 to 40 weeks of gestation. The findings of the present study were in agreement with the studies of Hadlocket al[11], Browne et al[12], Snijders RJ et al[13], Tagni ZD et al[17], Ashrafunnessa et al[18] and Figueraset al[14] who said that fetal Femur Length showed an increase with progress of gestation.

On comparing the means of femur length at different gestational age with that of other studies (Table - 1), there was discrepancy in size of femur length of present study with that of other studies. It might be due to relative smaller number of cases in the present study. The femur length may differ with population, racial characteristic, demographic features and nutrition of the population. Also the technical difference in measurement of femur length and difference in selection criteria of cases to include in the study may influence this discrepancy. Table 2 shows the distribution of number of cases showing difference between gestational age assessed from femur length and the gestational age assessed by Last Menstrual period. During Second Trimester, using Hadlock's fomula and Loughna P et al's[10] formula for femur length, 36 and 34 cases respectively assessed the same gestational age in completed weeks. Also, 78 and 75 observations assessed the gestational age within the range of \pm 1 week respectively. The difference was statistically not significant.

During Third Trimester, using Hadlock's fomula and Loughna P et al's[10] formula for femur length, 21 and 24 cases respectively assessed the same gestational age in completed weeks as by LMP. Also, 55 and 61 cases assessed the gestational age within the range of \pm 1 week respectively. The difference was statistically not significant.

Comparing the observations of second trimester with that of third trimester for femur length, it was found that there was no statistically significant difference in the number of observations assessing the same gestational age as well as assessing the gestational age within range of \pm 1 week in both trimester by Hadlock's or Loughna P et al's [10] formula. But it was found that accuracy of femur length in assessment of gestational age decreased from second trimester $(36 / 100)$ to third trimester (21/100). Also there was a shift towards higher inaccuracy in third trimester within range of 0 to -3 weeks as compared to second trimester.

As shown in Table 3, in second trimester, present study found femur length equally accurate in assessment of gestational age as Babuta $\mathrm{S}$ et al[2], but within the range of \pm 1 week Babuta $S$ et al[2] found femur length more accurate than present study. In third trimester, within the range 
of \pm 1 week, present study found femur length more accurate in assessment of gestational age.

The accuracy of femur length in assessment of gestational age decreased from second trimester to third trimester which was in agreement to Babuta $\mathrm{S}$ et al[2]. Macgregor SN et al[1] also quoted that Hadlock et al and Jeanty $P$ et al found accuracy of gestational age prediction based on $\mathrm{FL}$ is greatest in the second trimester and least near term.

\section{CONCLUSION}

In the present study, the mean of FL increased progressively from 13-40 weeks of gestation. During both second and third trimesters, Hadlock's formula and Loughna P's method were equally accurate to assess the gestational age. But femur length was more accurate in second trimester than in third trimester.

The positive aspects of present study were that it was population based and measurements were made according to standard protocols and method. The limiting factor in the present study was the relative small size of population and measurements were not done by single sonologist.

Due to discrepancy in femur length of the present study with that of other studies, while assessing gestational age using the reference charts of other population there were chances of significant error leading to under estimation or over estimation of gestational age. Therefore, like other studies the present study also found the need of fetal charts that were specific for individual population and ethnic group to determine gestational age and EDD to enable the development of better clinical guidelines for the present population.

\section{ABBREVIATIONS}

\section{GA - Gestational Age}

LMP - Last Menstrual Period

FL - Femur Length

EDD - Estimated Date of Delivery

\section{Conflicts of Interests: None}

\section{REFERENCES}

[1]. Macgregor SN, Sabbagha RE. Assesment of gestational age by ultrasound.Global library of women's medicine. 2008; DOI 10.3843 / GLOWM. 10199.
[2]. Babutta S, Chauhan S, Garg R, Bagarhatta M. Assessment of fetal gestational age in different trimesters from ultrasonographic measurements of various fetal biometric parameters. Journal of Anatomical Society of India 2013;62:40-46.

[3]. Leung TN, Pang MW, Daljit SS, Leung TY, Poon CF, Wong SM, Lau TK. Fetal biometry in ethnic Chinese: biparietal diameter, head circumference, abdominal circumference and femur length. Ultrasound Obstet Gynecol. 2008;31:321-327.

[4]. Chitty LS, Altman DG. Charts of fetal sized: Limb bones. BJOG: an International Journal of Obstetrics and Gynaecology 2002 August;109:919-929.

[5]. Altman DG, Chitty LS. New charts for ultrasound dating of pregnancy. Ultrasound Obstet Gynecol. 1997;10:174-191.

[6]. Morsy MM, Ashtokhy MAEI, Diab AE, Mansoor MA. Different measurements of Ultrasonic biometry of the Egyptian foetuses. ZUMJ 2012 September;18:861873.

[7]. Hidayat Sagvan KH. Sonographic evaluation of fetal femur length in gestational age estimation in DuhokIraq. Duhok Medical Journal 2009;3(1):4-9.

[8]. Kurmanavicius J, Wright EM, Royston P, Zimmermann $R$, Huch R, Huch A, Wisser J. Fetal Ultrasound biometry: 2. Abdomen and femur length reference values. BJOG 1999;106:136-143.

[9]. Lai FM, Yeo GS. Reference charts of foetal biometry in Asians. Singapore Med J 1995;36:628-636.

[10]. Loughna P, Chitty LS, Evans T, Chuleigh T. Fetal size and dating: Charts recommended for clinical obstetric practice. Ultrasound August 2009;17(3):161-167.

[11]. Hadlock FP, Harrist RB, Detter RL, Park SK. Fetal femur length as a predictor of menstrual age: sonographically measured. AJR Am J Roentgenol. 1982;138:875-878.

[12].Browne PC, Lewis $H$, Hammer LH, Clark WS. Sonographic fetal growth curves from an indigent population in Atlanta, Georgia. Part I. Singleton Pregnancies. Am J Perinatol. 1992;9:467-76.

[13]. Snijders RJ, Nicolaides KH. Fetal biometry at 14-40 weeks' gestation. Ultrasound Obstet Gynecol 1994;4:34-48.

[14]. Figueras F, Torrents M, Muñoz A, Comas C, Eugenia A, Carrera JM. Reference intervals for fetal biometrical parameters. European J Obstet Gynecol and Reproductive Biology 2002;105(1):25-30.

[15]. Hadlock FP, Harrist RB, Detter RL, Park SK. A prospective evaluation fetal femur length as a predictor of gestational age. Journal of Ultrasound Med. 1983;2:111-12.

[16]. Chitty LS, Altman DG, Henderson A, Campbell S. Charts for fetal size 4: Femur length. Br J Obstet Gynaecol (BJOG) 1994;101:132-135.

[17]. Tagni ZD, Ayuk NL, Kenla A, Shu D, Doh a, Kouam L, Gonsu FJ. Fetal ultrasound biometry in a Cameroonian population: study of femur length. Med Trop (Mars). 2002;62(5):521-4.

[18]. Ashrafunnessa, Jehan AH, Chowdhury SB, Sultana F, Haque JA, Khatun S, Karim MA. Construction of fetal 
charts for biparietal diameter, fetal abdominal circumference and femur length in Bangladeshi population. Bangladesh Med Res Counc Bull. 2003 Aug;29(2):67-77.

[19]. Seeds JW, Cefalo RC: Practical Obstetrical Ultrasound, p 57. Rockville, MD, Aspen, 1986. In Watson W and Seeds J. Diagnostic Obstetric Ultrasound. Glob. Libr. Women's med., 2008;DOI10.3843/ GLOWM.10199.
[20]. Beigi A, Zarrinkoub F. Ultrasound assessment of fetal biparietal diameter and femur length during normal pregnancy in Iranian women. International journal of gynecology and obstetrics 2000;69:237242.

[21].Statement on Normal Ultrasonic Fetal Measurements.[Internet] ASUM;2001 May. Report No.D7.Available from www.asum.com.au/newsite/ files/documents/policies/PS/D7policy.pdf

How to cite this article:

Monika Adhvaryu, Ankit Adhvaryu, Suresh P. Rathod, Pradip R. Chauhan. A STUDY OF SONOGRAPHIC EVALUATION OF FETAL FEMUR LENGTH FOR ESTIMATION OF GESTATIONAL AGE. Int J Anat Res 2019;7(2.3):6621-6626. DOI: $10.16965 /$ ijar.2019.189 